\title{
ON WEIGHTED WEAK TYPE MAXIMAL INEQUALITIES FOR MARTINGALES
}

\author{
M. KIKUCHI
}

Abstract. Let $\Phi$ be a Young function and $(u, v)$ a pair of weights on a probability space. We consider the inequality

$$
\sup _{\lambda \in(0, \infty)} \Phi(\lambda) \mathbb{E}[u:\{M f>\lambda\}] \leqslant \mathbb{E}\left[\Phi\left(C\left|f_{\infty}\right|\right) v\right]
$$

for martingales $f=\left(f_{n}\right)_{n \in \mathbb{Z}_{+}}$, where $M f=\sup _{n \in \mathbb{Z}_{+}}\left|f_{n}\right|$ and $f_{\infty}=\lim _{n} f_{n}$ a.s. We give some necessary and sufficient conditions for this inequality to hold, and extend Uchiyama's result.

\section{Mathematics subject classification (2000): 60G42, $60 \mathrm{G} 46$.}

Key words and phrases: weak type inequality, martingale, weight, Young function.

\section{REFERENCES}

[1] S. Bloom And R. Kerman, Weighted $L_{\Phi}$ integral inequalities for operators of Hardy type, Studia Math. 110 (1994), 35-52.

[2] A. BONAMI AND D. LÉPINGLE, Fonction maximale et variation quadratique des martingales en présence d'un poids, in: Séminaire de Probabilités, XIII, Lecture Notes in Math. 721, Springer, Berlin, 1979, pp. 294-306.

[3] M. A. Krasnosel'skiĬ And Ya. B. RutickIĬ, Convex functions and Orlicz spaces, P. Noordhoff Ltd., Groningen; Translated from the first Russian edition by Leo F. Boron.

[4] J. NEvEU, Discrete Parameter Martingales, North-Holland, Amsterdam; Translated from the French by T. P. Speed.

[5] A. UCHIYAMA, Weight functions on probability spaces, Tôhoku Math. J. (2) 30 (1978), 463-470. 